\title{
Diagnosis and treatment of anemia in patients with inflammatory bowel disease
}

\section{Victoria Mückea*, Marcus M. Mückea*, Tim Raine ${ }^{b * *}$, Dominik Bettenworth ${ }^{c * *}$}

J. W. Goethe University Hospital, Frankfurt, Germany; Addenbrooke's Hospital, University of Cambridge, Cambridge, UK; University Hospital Münster, Münster, Germany

\begin{abstract}
Anemia represents one of the most frequent complications in inflammatory bowel disease (IBD) and severely impairs the quality of life of affected patients. The etiology of anemia in IBD patients can be multifactorial, often involving a combination of iron deficiency (ID) and anemia of chronic disease (ACD). Although current guidelines recommend screening for and treatment of anemia in IBD patients, current observational data suggest that it still remains underdiagnosed and undertreated. Besides basic laboratory parameters (e.g. mean corpuscular volume, reticulocyte count, serum ferritin, transferrin saturation, etc.), the concentration of soluble transferrin receptor (sTfR) and novel parameters such as the sTfR/log ferritin index can guide the challenging task of differentiating between ID and ACD. Once identified, causes of anemia should be treated accordingly. This review summarizes our current understanding of anemia in IBD patients, including the underlying pathology, diagnostic approaches and appropriate anemia treatment regimens.
\end{abstract}

Keywords Inflammatory bowel disease, anemia, iron deficiency

Ann Gastroenterol 2016; 29 (4): 1-8

\section{Introduction}

Inflammatory bowel disease (IBD), including Crohn's disease (CD) and ulcerative colitis (UC), represents a spectrum of chronic, remitting disorders of the gastrointestinal tract of unknown etiology [1,2]. Besides symptoms primarily resulting from intestinal inflammation, IBD patients can develop various extra-intestinal manifestations [3]. Anemia appears to be one of the most frequent complications of IBD $[4,5]$. Reported prevalence rates are highly variable and may approach up to $74 \%[4,6]$. Heterogeneity in reported

Departments of anternal Medicine 1, J.W. Goethe University Hospital, Frankfurt, Germany (Victoria Mücke, Marcus M. Mücke); ${ }^{\mathrm{b}}$ Medicine, Addenbrooke's Hospital, University of Cambridge, Cambridge, UK (Tim Raine); ' Medicine B, University Hospital Münster, Münster, Germany (Dominik Bettenworth)

*Victoria Mücke and Marcus M. Mücke share equal first authorship

${ }^{*}$ Tim Raine and Dominik Bettenworth share equal senior authorship

Conflict of Interest: None

Correspondence to: Dominik Bettenworth, MD, Department of Medicine B, University Hospital Münster, Albert-Schweitzer-Campus 1, D-48149 Münster, Germany, Tel.: +49 251834 7661,

Fax: +49 251834 7570, e-mail: dominik.bettenworth@ukmuenster.de

Received 3 June 2016; accepted 27 July 2016;

published online 6 September 2016

DOI: http://dx.doi.org/10.20524/aog.2016.0083 rates in part reflects poorly standardized definitions of anemia. Although the World Health Organization (WHO) anemia criteria [7] are widely accepted (Table 1), they have been questioned on the basis of differences in ethnicity or local environment $[8,9]$. Additionally, in a recent survey across European countries, Stein et al revealed that differences between patient cohorts may contribute to diverging data. For example, whilst reported prevalence rates amongst outpatients range up to $16 \%$, similar data for hospitalized patients exceed $65 \%[10,11]$. A recent meta-analysis of individual patient data from 2192 European patients determined the overall prevalence of anemia in IBD patients to be $24 \%$, with a reported occurrence of severe anemia in $2.75 \%$ of patients analyzed. In the same study, the overall prevalence was higher in CD than in UC patients [12].

Unfortunately, over the past decades anemia in IBD has received little attention [13], reflected perhaps in only marginal coverage in former international guidelines for the management of IBD [14]. In contrast, in recent years the topic has moved into the spotlight, because there is a growing body of evidence that anemia plays a key role in affecting IBD patients' quality of life (QOL). In 2014, Danese et al analyzed anemia-related symptoms from an IBD patient's perspective [15]. Symptoms widely reported by the 613 participants included fatigue, weakness, difficulties in concentrating, depressive mood, breathlessness, and sleeping difficulties. Patients affected by fatigue reported a major negative impact on daily life, including physical activities, productivity and home life (76\%, 63\% and $60 \%$, respectively). Several other studies have confirmed that 
anemia in IBD further worsens an already impaired QOL, while its treatment significantly increases QOL [16-18].

Although current guidelines recommend the treatment of anemia in IBD patients, recent evidence suggests that anemia remains underdiagnosed and undertreated. For example, Blumenstein et al revealed that in Germany $56.5 \%$ of IBD patients with anemia had not received adequate treatment [19]. Likewise, a web-based questionnaire of IBD patients showed that one third of those with anemia had not been treated accordingly [15]. Additionally, in a recent survey across 9 European countries, Stein et al revealed a high frequency of iron deficiency (ID) among IBD patients [20]. Moreover, the authors of the latter study observed that gastroenterologists, in clinical practice, frequently deviate from international guidelines concerning iron supplementation in IBD patients.

\section{Pathophysiology of anemia in IBD}

In IBD patients, anemia represents a systemic complication or extra-intestinal manifestation that can be multifactorial

Table 1 Minimum hemoglobin and hematocrit levels used to define anemia in people living at sea level [WHO, UNICEF, UNO. Iron deficiency anemia: assessment, prevention and control. Report of a joint WHO/UNICEF/UNU consultation. Geneva: World Health Organization; 1998]

\begin{tabular}{lccc}
\hline Age or sex group & $\begin{array}{c}\text { Hemoglobin } \\
(\mathrm{g} / \mathrm{dL})\end{array}$ & $\begin{array}{c}\text { Hemoglobin } \\
(\mathrm{mmol} / \mathrm{dL})\end{array}$ & $\begin{array}{c}\text { Hematocrit } \\
(\%)\end{array}$ \\
\hline Children 1/2 to 5 years & 11.0 & 6.83 & 33 \\
\hline Children 5 to 11 years & 11.5 & 7.14 & 34 \\
Children 12 to 13 years & 12.0 & 7.45 & 36 \\
Non-pregnant women & 12.0 & 7.45 & 36 \\
Pregnant women & 11.0 & 6.83 & 33 \\
Men & 13.0 & 8.07 & 39 \\
\hline
\end{tabular}

in origin (Fig. 1), but is typically caused by a combination of ID and anemia of chronic disease (ACD) [21]. It is well known that a significant number of IBD patients develop ID. A combination of chronic intestinal blood loss, dietary restrictions and/or iron malabsorption caused by mucosal inflammation or surgical bowel resections (especially in CD patients) leads to a disequilibrium of iron demand and absorption $[4,11,22]$.

Iron is an essential mineral that is mostly bound in hemoglobin $(\mathrm{Hb})$. After ingestion, dietary iron is reduced from its ferric $\left(\mathrm{Fe}^{3+}\right)$ to its ferrous $\left(\mathrm{Fe}^{2+}\right)$ form and absorbed predominantly in the duodenum at the apical surface of enterocytes through the divalent metal transporter. Although dietary iron is poorly absorbed, a major additional source of iron in the diet comes from that bound to animal heme, which is taken up into cells by a poorly understood mechanism and degraded to release bound iron. Subsequently, iron undergoes transfer through the basolateral membrane via the dedicated ferroportin channel, before oxidation back to $\mathrm{Fe}^{3+}$. In the circulation, elemental iron is almost entirely bound by transferrin and distributed throughout the body $[11,23]$. Iron absorption is crucially regulated by the peptide hepcidin which is principally produced in the liver [24]. It reduces iron absorption in cases of iron overload or upon induction by proinflammatory cytokines, including interleukin (IL) -6 and bone morphogenetic protein $[25,26]$. Notably, these proinflammatory cytokines are elevated in active IBD, while hepcidin levels can be further increased by malignancies, autoimmune diseases (e.g. rheumatoid arthritis) or chronic kidney diseases [27-29]. Elevated levels of hepcidin then result in internalization and degradation of ferroportin, leading to impaired iron absorption [30] as well as to iron retention in macrophages and monocytes [31]. Recently, several studies confirmed increased serum levels of hepcidin in IBD patients. For example, Basseri et al observed a strong correlation between hepcidin expression and proinflammatory IL-6 levels in patients with $\mathrm{CD}$ [32]. In line with this observation, Semrin et al demonstrated that intestinal iron absorption was

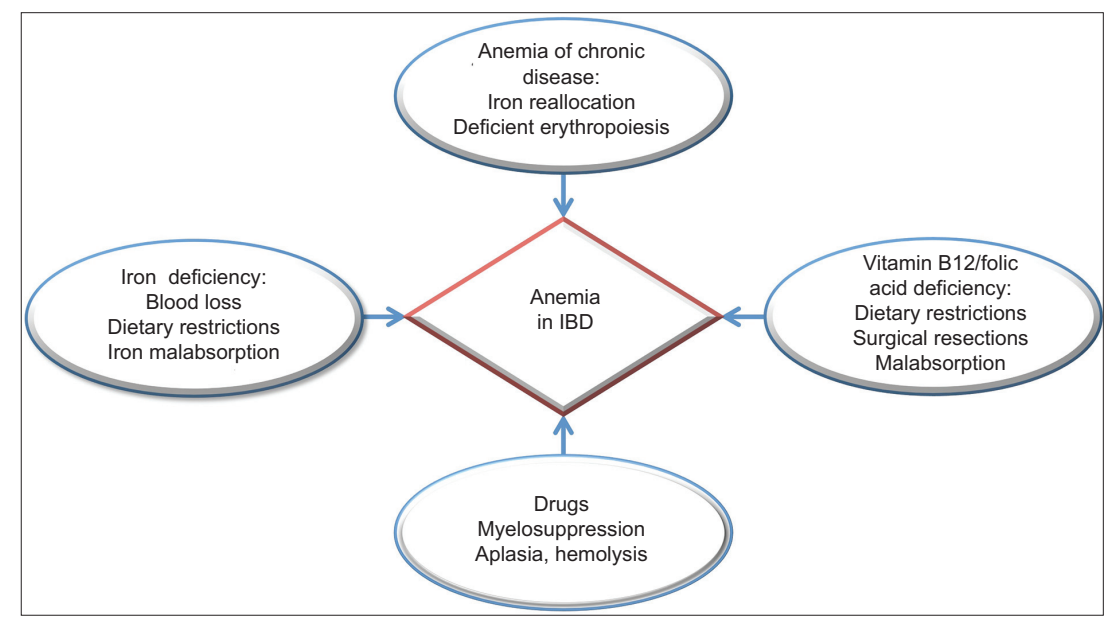

Figure 1 Predominant causes of anemia in inflammatory bowel disease (IBD). While iron-deficiency anemia of chronic diseases and mixed forms are the most common causes for anemia in IBD patients, lack of vitamin B12 as well as folic acid and IBD-related medication can also contribute to anemia development 
decreased in $\mathrm{CD}$ patients with active disease compared to $\mathrm{CD}$ patients in remission [33].

ACD represents the second major cause of anemia in IBD. Although its pathophysiology remains complex, three core mechanisms have been identified which jointly culminate in ACD: 1) iron redistribution out of the serum due to increased hepcidin levels, including retention in macrophages and monocytes (blurring the differentiation between ID and ACD, see above);2) deficient maturation and proliferation of erythroid progenitor cells; and 3) a reduced erythrocyte lifespan [34]. Additionally, several cytokines that are overexpressed in chronic diseases, such as tumor necrosis factor (TNF)- $\alpha$, IL-1 or interferon (IFN) $-\gamma$, further contribute to this process. In 1987, Roodmann et al were the first to report that TNF- $\alpha$ inhibits erythropoiesis [35]. It is now known that TNF- $\alpha$ not only directly inhibits erythropoiesis [36], but also indirectly impairs this process by downregulation of erythropoietin $[37,38]$. Likewise, hepcidin and IL-1 are also capable of reducing the concentration of erythropoietin [38,39]. Additionally, IFN- $\gamma$ further drives the development of anemia by inhibiting erythroid colony growth [40], shortening the lifespan of erythrocytes via increased turnover in the spleen [41], and increasing apoptosis mediated by TNF-related apoptosisinducing ligand or TNF-like weak inducer of apoptosis in erythroid progenitor cells $[42,43]$.

Aside from ID and ACD, anemia in IBD patients can result from impaired vitamin B12 and folic acid absorption. Vitamin B12 and folic acid deficiency is found in up to $33 \%$ and $29 \%$, respectively, of patients with CD [44-47]. Reasons include dietary restrictions, as well as impairment of ileal absorption (typically through a combination of ileal inflammation, bacterial overgrowth and/or surgical resection, leading to reduced vitamin B12 and folic acid absorption) $[45,46]$. In UC, vitamin B12 and folic acid deficiency is less common but can occur in up to $16 \%$ and $8.6 \%$, respectively [44-47]. Possible causes include ileal dysfunction following proctocolectomy and ileal pouch-anal anastomosis, bacterial overgrowth and reduced intestinal transit time $[44,48]$.

Finally, anemia can also occur as a side effect of IBD therapeutics. While toxicity of thiopurines towards the bone marrow is widely recognized and appears in approximately $3 \%$ of cases per patient/year of treatment $[49,50]$, anemia has also been found to be related to sulfasalazine therapy through reduced folate absorption and aplasia or hemolysis, although this is rarely reported [51,52].

\section{Diagnosis of anemia in IBD patients}

In humans, multiple factors, such as age, sex, ethnicity, pregnancy, environment and nutrition, influence $\mathrm{Hb}$ levels [53,54]. In general, the WHO defines anemia as a decline in blood $\mathrm{Hb}$ according to the reference levels given in Table 1. These cutoff levels apply equally to IBD patients, as the definitions do not vary according to comorbidities. Considering the high prevalence of anemia in chronic inflammatory diseases, the recently published European Crohn's and Colitis Organization (ECCO) guideline on anemia recommends regular screening, according to disease severity and activity [21]. More specifically, anemia assessment in outpatients with active inflammation (high elevated inflammatory biomarkers or significant endoscopic proof of disease activity) should be performed at least every three months, whereas screening intervals in outpatients who show few signs of systemic inflammation or are in remission can be extended to every six to twelve months. Special attention should be paid to children and adolescents [55]. Common diagnostic markers for anemia assessment may be applied to patients without clinical, endoscopic or biochemical evidence of active disease. In contrast, in IBD patients who have active disease, are receiving ongoing therapy, or have undergone extensive small bowel resection, important parameters for the assessment of anemia, such as erythrocyte indices, ferritin and transferrin saturation (TfS), do not always afford sufficient accuracy. It should be remembered that ferritin is an acutephase protein that is increased in the context of ongoing systemic inflammation [56]. Furthermore, differentiation between the two most frequent types of anemia in IBD patients, ID and ACD, remains challenging, especially since both conditions frequently coexist.

Traditionally, the distinction between different causes of anemia is based on a hematological algorithm starting with the interpretation of the mean corpuscular volume (MCV). Accordingly, micro-, macro- or normocytic erythrocyte conditions may hint at different causes for anemia. Besides $\mathrm{MCV}$, basic laboratory parameters should include reticulocyte count, differential blood cell count, red cell distribution width, and serum ferritin, TfS and C-reactive protein (CRP) concentrations [21]. In patients with postoperative $C D$ or severe ileitis, serum levels of vitamin B12 and folic acid should also be evaluated. In patients with signs of hemolysis or significant comorbidities, haptoglobin, the percentage of hypochromic red cells, reticulocyte $\mathrm{Hb}$, lactate dehydrogenase, soluble transferrin receptor (sTfR), creatinine, and urea should be determined accordingly [21]. Some authors have also emphasized a key potential role for early markers of impaired erythropoiesis markers, such as the $\mathrm{Hb}$ content in reticulocytes $(\mathrm{CHr})$ or reticulocyte $\mathrm{Hb}$ equivalent, measures that are not available as part of conventional laboratory tests and that are further discussed in the outlook section [57].

\section{ID anemia in IBD patients}

Low serum ferritin levels $(<30 \mu \mathrm{g} / \mathrm{L})$, high transferrin levels and a decreased MCV index are routinely used to screen for ID [58]. In IBD-patients, these parameters may not always allow for reliable conclusions, because of overlapping causes of anemia and multiple confounding factors (see above). In particular, active inflammation can result in falsely normal or elevated ferritin levels as part of an acute-phase reaction [5]. Under chronic inflammatory conditions, other parameters of low iron stores are also less interpretable, as a result of changes such as increased platelet counts [59] or low transferrin levels [60]. In these cases, it is important to consider that serum ferritin levels up to $100 \mu \mathrm{g} / \mathrm{L}$ do not adequately exclude 
ID [61]. Therefore, the concentration of sTfR may indicate the status of iron supply more precisely, since this parameter is not influenced by chronic inflammation [62]. Recently, the ratio of sTfR to the logarithm of serum ferritin (sTfR/log ferritin index) has been reported as providing more accuracy in differentiating ID anemia from ACD $[63,64]$. For example, a prospective multicenter observational trial in a cohort of 145 non-IBD patients with anemia demonstrated the utility of the sTfR/log ferritin index [65]. Skikne et al demonstrated that subjects with ID anemia or ACD + ID anemia had significantly higher sTfR and sTfR/log ferritin index values than subjects with ACD. ROC curves produced cutoffs of $21 \mathrm{nmol} / \mathrm{L}$ for sTfR and 14 (using nmol/L) for the sTfR/log ferritin index. The $s \mathrm{TfR} / \log$ ferritin index was superior to sTfR.

\section{ACD in IBD patients}

Functional ID is a state in which there is insufficient iron incorporation during erythropoiesis, despite normal total body iron stores, and it is a major component of ACD. Therefore, besides "true" ID anemia, functional ID should be considered if serum ferritin is $>100 \mu \mathrm{g} / \mathrm{L}$ and TfS below $20 \%$ [21]. Again, sTfR/log ferritin may help discriminate absolute from functional ID anemia [34,66]. In patients with evidence of inflammation and intermediate serum ferritin levels $(<100 \mu \mathrm{g} / \mathrm{L}$ but $>30 \mu \mathrm{g} / \mathrm{L})$, a value of $s$ TfR/log ferritin $>2$ may indicate a combined anemic status, whereas a ratio $<2$ is consistent with normal total body iron stores [34].

\section{Non-ID anemia in IBD patients}

As described above, there are several additional important causes of $\mathrm{Hb}$ deprivation in patients with IBD. Especially in cases of macrocytic anemia, vitamin B12 and folic acid level measurements should be performed during screening visits [44]. Additionally, myelosuppressive medication, including thiopurines and sulfasalazine, should always be considered in the diagnostic workup of anemia $[49,52]$.

\section{Treatment of anemia in IBD}

Given that anemia significantly affects patients' QOL and increases disease severity and mortality rates, therapeutic interventions aiming to normalize $\mathrm{Hb}$ levels play a crucial part in the clinical management of IBD patients [61]. Physicians should be aware of anemia in IBD patients and should treat the underlying causes.

\section{Iron therapy in IBD}

Recentguidelinesstrongly recommendironsupplementation in patients with confirmed ID anemia $[11,67,68]$. The normalization of $\mathrm{Hb}$ levels and repletion of iron stores are considered as final therapeutic goals. More specifically, a $\mathrm{Hb}$ increase of $>2 \mathrm{~g} / \mathrm{dL}$ and a transferrin saturation of $>30 \%$ within 4 weeks are regarded as adequate therapeutic responses $[11,69]$. Iron supplementation in IBD patients without manifest anemia is still debated and should be further evaluated in clinical trials, especially with regard to tolerance of therapy.

Normal diets usually provide sufficient iron supplies in the form of elemental and heme iron. As already discussed, in patients with active IBD, the inflammation of the mucosa leads to maldigestion, malabsorption and changing nutrition habits $[33,70,71]$, which may aggravate ID and make exclusive nutritional supplementation impossible. Nevertheless, oral iron substitution can be effective in IBD patients with mild disease activity and mild anemia [72,73]. For reasons of widespread availability, low cost and established safety profile, many physicians tend to favor oral iron substitution as firstline therapy. Frequently used oral iron supplements are ferrous fumarate (325 mg tablets containing $106 \mathrm{mg}$ elemental iron per tablet), ferrous sulfate ( $325 \mathrm{mg}$ tablets containing $65 \mathrm{mg}$ elemental iron per tablet), and ferrous gluconate (325 mg tablets containing $36 \mathrm{mg}$ elemental iron per tablet).

However, in the light of several reports of adverse events [74] and additional mucosal harm [72] in IBD patients during oral iron replacement therapy, oral supplementation must be evaluated in terms of effectiveness and tolerability [75-77]. Animal trials indicate that oral and rectal iron intake can lead to an aggravation of disease activity through the increased production of proinflammatory cytokines, such as IL-1, IL-6, TNF- $\alpha$ and IFN- $\gamma$ [78]. This may be linked to increased flux in the classic $\mathrm{Fe}^{2+}$-catalyzed Fenton reaction that triggers the production of reactive oxygen species by neutrophils in the mucosa [79].

For these reasons, intravenous iron supplementation is currently still favored in IBD patients with ID anemia, especially in cases of severe anemia $(\mathrm{Hb}<10 \mathrm{~g} / \mathrm{L})$, or inadequate response to or intolerance of oral supplementations $[80,81]$, not least because it is well-tolerated by most patients [15]. Furthermore, intravenously administered iron does not deteriorate disease activity in IBD patients [80,82]. In early trials, modern preparations of ferric iron, such as Monofer ${ }^{\circledast}$ (iron isomaltoside) and Ferinject ${ }^{\oplus}$ (ferric carboxymaltose) were well tolerated in terms of the acute toxicity profile, efficacy and tolerance in IBD patients. In general, newer non-dextran intravenous formulations seem to be superior to preparations containing elemental iron complexed with dextrans, especially in terms of reduced rates of anaphylactoid reactions. In practice, this means that non-dextran formulations can be given at a faster rate and are not complicated by the requirement for the application of a test dose [73,83-85].

Previously, the Ganzoni formula has been widely used to estimate iron requirements and dosage, although this has been criticized as inconvenient, inconsistent and inaccurate [21]. More recently, a novel scheme of total iron calculation has been proposed and provides a simple and efficient dosing regimen (Table 2, [84]). Although this scheme has only been evaluated for the dosing of intravenous ferric carboxymaltose, physicians have broadly adopted it for use with other intravenous iron 
Table 2 Estimated total iron need in inflammatory bowel disease patients with iron-deficiency anemia [75]

\begin{tabular}{lcc}
\hline Hemoglobin g/dL & Body weight $<70 \mathrm{~kg}$ & Body weight $\geq 70 \mathrm{~kg}$ \\
\hline $10-12$ (women) & $1000 \mathrm{mg}$ & $1500 \mathrm{mg}$ \\
$10-13$ (men) & $1000 \mathrm{mg}$ & $1500 \mathrm{mg}$ \\
$7-10$ & $1500 \mathrm{mg}$ & $2000 \mathrm{mg}$ \\
\hline
\end{tabular}

products. Adjustments may be made in patients with very severe anemia $(<7.0 \mathrm{~g} / \mathrm{dL})$. In these patients, experts suggest an additional dosage of 500-1000 mg according to evaluated tolerability [86].

After successful initial treatment of ID anemia, IBD patients are still at an increased risk of anemia recurrence and may benefit from prophylactic iron substitution [87]. Again, initial infusions with ferric carboxymaltose (Ferinject ${ }^{\circledast}$ ) seem to adequately prevent recurrences [88]. Recent data suggest an intravenous iron re-treatment as soon as serum ferritin drops below $100 \mu \mathrm{g} / \mathrm{L}$ or recurrence of anemia occurs [84]. Notably, however, Ali et al demonstrated that up to 8 weeks after intravenous iron-dextran therapy, ferritin levels may not sufficiently reflect the availability of iron in patients' bone marrow [89], suggesting that clinicians should avoid assessing the response too soon after therapy.

\section{Therapy of ACD in IBD}

After diagnosing ACD and addressing any coincident ID, treatment of ACD should focus on optimization of IBD treatment to control disease activity. In addition, concurrent infections, inflammation or malignancies should also be considered and addressed when identified [21]. Furthermore, erythropoietin-stimulating agents in combination with intravenous iron supplementation may additionally be administered with beneficial effects in ACD anemia [5,90,91]. In some studies, erythropoietin has also already been shown to attenuate intestinal inflammation and to promote epithelial tissue regeneration [92]. Additionally, TNF- $\alpha$-induced bone marrow suppression may require the use of anti-TNF therapy to support bone marrow output [93].

\section{Treatment of trace element and vitamin deficiency anemia}

In patients with active IBD, or especially after ileal resection, signs of mixed anemia or high MCV levels should be seen as an indication for the measurement and direct supplementation of vitamin B12 and folic acid [21].

\section{Outlook}

As mentioned above, the sTfR/log ferritin index is seen as a promising biomarker of iron availability and has been integrated into new diagnostic algorithms to differentiate ID anemia from ACD $[63,65]$. Furthermore, Enko et al discussed the accuracy of the combined evaluation of the iron-transporter binding protein hepcidin-25, along with ferritin [94] and proposed hepcidin-25 quantification, to assess functional ID, particularly in patients with elevated serum CRP levels $>5 \mathrm{mg} / \mathrm{L}$ [95].

Furthermore, characterization of the reticulocyte function by using novel indices such as $\mathrm{CHr}$ can allow rapid detection of ID and additionally provides a measure of recent bone marrow output. This may be of particular value under situations of rapid changes (e.g. assessing response to recent iron therapy), since conventional erythrocyte indices will be affected by the comparatively long lifespans of mature erythrocytes, which extend up to 120 days [96]. Moreover, Urrechaga et al described a method for the early detection of coincident ID in patients with established ACD through measuring the percentage of hypochromic erythrocytes (\%Hypo-He), reporting that the technique showed promising reliability. This parameter visualizes the portion of mature erythrocyte red cells with inadequate $\mathrm{Hb}$ loading and is said to increase earlier than common ID biomarkers [97]. Importantly, both $\mathrm{CHr}$ and \%Hypo$\mathrm{He}$ are likely to be in the normal range in uncomplicated and non-overlapping ACD [96,97]. Nevertheless, clinical trials in IBD patients are needed to confirm the reliability, validity and necessity of the all above-mentioned potential new biomarkers.

Novel preparations have been designed to address intolerance to oral iron supplementation. For example, ferric maltol has been shown to provide satisfactory efficiency in mild to moderate anemia in IBD and good tolerability rates, even in patients who have previously been intolerant to other oral supplementation drugs [98]. Reaching the intestinal mucosa as a stable complex, ferric iron with maltol seems to allow a more efficient iron uptake than ferrous iron salts $[99,100]$.

Other novel treatment options for ACD in IBD focus on hepcidin antagonism. Preliminary results from preclinical studies in monkeys show promising effects on specific iron mobilization $[101,102]$, but need to be further evaluated in clinical trials in human patients.

\section{Concluding remarks}

ID anemia is frequently observed in IBD patients. Thus, all IBD patients should be screened on a regular basis (in accordance with disease severity) for ID and ID anemia. Complete blood count, serum ferritin and CRP value constitute an appropriate screening standard, while the detection of decreased $\mathrm{Hb}$ values warrants a more extended diagnostic anemia workup. In IBD patients with ID anemia, iron substitution remains indispensable and the advantages as well as the disadvantages of oral and intravenous formulations should be considered carefully. 


\section{References}

1. Baumgart DC, Sandborn WJ. Crohn's disease. Lancet 2012;380:1590-1605.

2. Ordás I, Eckmann L, Talamini M, Baumgart DC, Sandborn WJ. Ulcerative colitis. Lancet 2012;380:1606-1619.

3. Ott C, Schölmerich J. Extraintestinal manifestations and complications in IBD. Nat Rev Gastroenterol Hepatol 2013;10:585-595.

4. Kulnigg S, Gasche C. Systematic review: managing anaemia in Crohn's disease. Aliment Pharmacol Ther 2006;24:1507-1523.

5. Gisbert JP, Gomollón F. Common misconceptions in the diagnosis and management of anemia in inflammatory bowel disease. Am J Gastroenterol 2008;103:1299-1307.

6. Wilson A, Reyes E, Ofman J. Prevalence and outcomes of anemia in inflammatory bowel disease: a systematic review of the literature. Am J Med 2004;116 Suppl 7A:44S-49S.

7. Nutritional anaemias. Report of a WHO scientific group. World Health Organ Tech Rep Ser 1968;405:5-37.

8. Patel KV, Harris TB, Faulhaber M, et al. Racial variation in the relationship of anemia with mortality and mobility disability among older adults. Blood 2007;109:4663-4670.

9. Beutler E, Waalen J. The definition of anemia: What is the lower limit of normal of the blood hemoglobin concentration? Blood 2006;107:1747-1750.

10. Gomollón F, Gisbert JP. Anemia and inflammatory bowel diseases. World J Gastroenterol 2009;15:4659-4665.

11. Stein J, Hartmann F, Dignass AU. Diagnosis and management of iron deficiency anemia in patients with IBD. Nat Rev Gastroenterol Hepatol 2010;7:599-610.

12. Filmann N, Rey J, Schneeweiss S, et al. Prevalence of anemia in inflammatory bowel diseases in european countries: a systematic review and individual patient data meta-analysis. Inflamm Bowel Dis 2014;20:936-945.

13. Gasche C. Anemia in IBD: the overlooked villain. Inflamm Bowel Dis 2000;6:142-150; discussion 151.

14. Carter MJ, Lobo AJ, Travis SP; IBD Section, British Society of Gastroenterology. Guidelines for the management of inflammatory bowel disease in adults. Gut 2004;53 Suppl 5:V1-16.

15. Danese S, Hoffman C, Vel S, et al. Anaemia from a patient perspective in inflammatory bowel disease: results from the European Federation of Crohn's and Ulcerative Colitis Association's online survey. Eur J Gastroenterol Hepatol 2014;26:1385-1391.

16. Pizzi LT, Weston CM, Goldfarb NI, et al. Impact of chronic conditions on quality of life in patients with inflammatory bowel disease. Inflamm Bowel Dis 2006;12:47-52.

17. Wells CW, Lewis S, Barton JR, Corbett S. Effects of changes in hemoglobin level on quality of life and cognitive function in inflammatory bowel disease patients. Inflamm Bowel Dis 2006; 12:123-130

18. Gisbert JP, Bermejo F, Pajares R, et al. Oral and intravenous iron treatment in inflammatory bowel disease: hematological response and quality of life improvement. Inflamm Bowel Dis 2009;15:1485-1491.

19. Blumenstein I, Dignass A, Vollmer S, Klemm W, Weber-Mangal S, Stein J. Current practice in the diagnosis and management of IBDassociated anaemia and iron deficiency in Germany: the German AnaemIBD Study. J Crohns Colitis 2014;8:1308-1314.

20. Stein J, Bager P, Befrits R, et al. Anaemia management in patients with inflammatory bowel disease: routine practice across nine European countries. Eur J Gastroenterol Hepatol 2013;25:1456-1463.

21. Dignass AU, Gasche C, Bettenworth D, et al. European consensus on the diagnosis and management of iron deficiency and anaemia in inflammatory bowel diseases. J Crohns Colitis 2015;9:211-222.
22. Murawska N, Fabisiak A, Fichna J. Anemia of chronic disease and iron deficiency anemia in inflammatory bowel diseases: Pathophysiology, diagnosis, and treatment. Inflamm Bowel Dis 2016;22:1198-208.

23. Anderson GJ. Non-transferrin-bound iron and cellular toxicity. $J$ Gastroenterol Hepatol 1999;14:105-108.

24. Atanasiu V, Manolescu B, Stoian I. Hepcidin-central regulator of iron metabolism. Eur J Haematol 2007;78:1-10.

25. Besson-Fournier C, Latour C, Kautz L, et al. Induction of activin B by inflammatory stimuli up-regulates expression of the ironregulatory peptide hepcidin through Smad1/5/8 signaling. Blood 2012;120:431-439.

26. Nemeth E, Rivera S, Gabayan V, et al. IL-6 mediates hypoferremia of inflammation by inducing the synthesis of the iron regulatory hormone hepcidin. J Clin Invest 2004;113:1271-1276.

27. Demirag MD, Haznedaroglu S, Sancak B, et al. Circulating hepcidin in the crossroads of anemia and inflammation associated with rheumatoid arthritis. Intern Med 2009;48:421-426.

28. Hohaus S, Massini G, Giachelia M, et al. Anemia in Hodgkin's lymphoma: the role of interleukin-6 and hepcidin. J Clin Oncol 2010;28:2538-2543.

29. Tsuchiya $K$, Nitta $K$. Hepcidin is a potential regulator of iron status in chronic kidney disease. Ther Apher Dial 2013;17:1-8.

30. Nemeth E, Tuttle MS, Powelson J, et al. Hepcidin regulates cellular iron efflux by binding to ferroportin and inducing its internalization. Science 2004;306:2090-2093.

31. Theurl I, Mattle V, Seifert M, Mariani M, Marth C, Weiss G. Dysregulated monocyte iron homeostasis and erythropoietin formation in patients with anemia of chronic disease. Blood 2006;107:4142-4148.

32. Basseri RJ, Nemeth E, Vassilaki ME, et al. Hepcidin is a key mediator of anemia of inflammation in Crohn's disease. J Crohns Colitis 2013;7:e286-e291.

33. Semrin G, Fishman DS, Bousvaros A, et al. Impaired intestinal iron absorption in Crohn's disease correlates with disease activity and markers of inflammation. Inflamm Bowel Dis 2006;12:1101-1106.

34. Weiss G, Goodnough LT. Anemia of chronic disease. N Engl J Med 2005;352:1011-1023.

35. Roodman GD, Bird A, Hutzler D, Montgomery W. Tumor necrosis factor-alpha and hematopoietic progenitors: effects of tumor necrosis factor on the growth of erythroid progenitors CFU-E and BFU-E and the hematopoietic cell lines K562, HL60, and HEL cells. Exp Hematol 1987;15:928-935.

36. Rusten LS, Jacobsen SE. Tumor necrosis factor (TNF)-alpha directly inhibits human erythropoiesis in vitro: role of p55 and p75 TNF receptors. Blood 1995;85:989-996.

37. Imagawa S, Yamamoto M, Miura Y. Negative regulation of the erythropoietin gene expression by the GATA transcription factors. Blood 1997;89:1430-1439.

38. Jelkmann W. Proinflammatory cytokines lowering erythropoietin production. J Interferon Cytokine Res 1998;18:555-559.

39. Dallalio G, Law E, Means RT Jr. Hepcidin inhibits in vitro erythroid colony formation at reduced erythropoietin concentrations. Blood 2006; 107:2702-2704.

40. Wang CQ, Udupa KB, Lipschitz DA. Interferon-gamma exerts its negative regulatory effect primarily on the earliest stages of murine erythroid progenitor cell development. J Cell Physiol 1995; 162:134-138.

41. Libregts SF, Gutiérrez L, de Bruin AM, et al. Chronic IFN- $\gamma$ production in mice induces anemia by reducing erythrocyte life span and inhibiting erythropoiesis through an IRF-1/PU.1 axis. Blood 2011;118:2578-2588.

42. Dai CH, Price JO, Brunner T, Krantz SB. Fas ligand is present in human erythroid colony-forming cells and interacts with Fas induced by interferon gamma to produce erythroid cell apoptosis. Blood 1998;91:1235-1242. 
43. Felli N, Pedini F, Zeuner A, et al. Multiple members of the TNF superfamily contribute to IFN-gamma-mediated inhibition of erythropoiesis. J Immunol 2005;175:1464-1472.

44. Bermejo F, Algaba A, Guerra I, et al. Should we monitor vitamin b12 and folate levels in Crohn's disease patients? Scand J Gastroenterol 2013;48:1272-1277.

45. Headstrom PD, Rulyak SJ, Lee SD. Prevalence of and risk factors for vitamin $\mathrm{B}(12)$ deficiency in patients with Crohn's disease. Inflamm Bowel Dis 2008;14:217-223.

46. Ward MG, Kariyawasam VC, Mogan SB, et al. Prevalence and risk factors for functional vitamin B12 deficiency in patients with Crohn's disease. Inflamm Bowel Dis 2015;21:2839-2847.

47. Yakut M, Ustün Y, Kabaçam G, Soykan I. Serum vitamin B12 and folate status in patients with inflammatory bowel diseases. Eur J Intern Med 2010;21:320-323.

48. M'Koma AE. Follow-up results of hematology data before and after restorative proctocolectomy. Clinical outcome. Dis Colon Rectum 1994;37:932-937.

49. Gisbert JP, Gomollón F. Thiopurine-induced myelotoxicity in patients with inflammatory bowel disease: a review. Am J Gastroenterol 2008;103:1783-1800.

50. Karran P. Thiopurines, DNA damage, DNA repair and therapyrelated cancer. Br Med Bull 2006;79-80:153-170.

51. Taffet SL, Das KM. Sulfasalazine. Adverse effects and desensitization. Dig Dis Sci 1983;28:833-842.

52. Ransford RA, Langman MJ. Sulphasalazine and mesalazine: serious adverse reactions re-evaluated on the basis of suspected adverse reaction reports to the Committee on Safety of Medicines. Gut 2002;51:536-539.

53. Cappellini MD, Motta I. Anemia in clinical practice-definition and classification: Does hemoglobin change with aging? Semin Hematol 2015;52:261-269.

54. Artz A, Dong X. Defining anemia by race using epidemiologic data. Blood 2008;111:2941.

55. Goodhand JR, Kamperidis N, Rao A, et al. Prevalence and management of anemia in children, adolescents, and adults with inflammatory bowel disease. Inflamm Bowel Dis 2012;18:513-519.

56. Gabay C, Kushner I. Acute-phase proteins and other systemic responses to inflammation. $N$ Engl J Med 1999;340:448-454

57. Brugnara C. Reticulocyte cellular indices: a new approach in the diagnosis of anemias and monitoring of erythropoietic function. Crit Rev Clin Lab Sci 2000;37:93-130.

58. Dubois RW, Goodnough LT, Ershler WB, Van Winkle L, Nissenson AR. Identification, diagnosis, and management of anemia in adult ambulatory patients treated by primary care physicians: evidence-based and consensus recommendations. Curr Med Res Opin 2006;22:385-395.

59. Voudoukis E, Karmiris K, Oustamanolakis P, et al. Association between thrombocytosis and iron deficiency anemia in inflammatory bowel disease. Eur $J$ Gastroenterol Hepatol 2013;25:1212-1216.

60. Cronin CC, Shanahan F. Anemia in patients with chronic inflammatory bowel disease. Am J Gastroenterol 2001; 96:2296-2298.

61. Gasche C, Lomer MC, Cavill I, Weiss G. Iron, anaemia, and inflammatory bowel diseases. Gut 2004;53:1190-1197.

62. Beguin Y. Soluble transferrin receptor for the evaluation of erythropoiesis and iron status. Clin Chim Acta 2003;329:9-22.

63. Oustamanolakis P, Koutroubakis IE. Soluble transferrin receptorferritin index is the most efficient marker for the diagnosis of iron deficiency anemia in patients with IBD. Inflamm Bowel Dis 2011;17:E158-E159.

64. Infusino I, Braga F, Dolci A, Panteghini M. Soluble transferrin receptor (sTfR) and sTfR/log ferritin index for the diagnosis of iron-deficiency anemia. A meta-analysis. Am J Clin Pathol 2012;138:642-649.
65. Skikne BS, Punnonen K, Caldron PH, et al. Improved differential diagnosis of anemia of chronic disease and iron deficiency anemia: a prospective multicenter evaluation of soluble transferrin receptor and the sTfR/log ferritin index. Am J Hematol 2011;86:923-927.

66. Oustamanolakis P, Koutroubakis IE, Messaritakis I, Niniraki M, Kouroumalis EA. Soluble transferrin receptor-ferritin index in the evaluation of anemia in inflammatory bowel disease: a casecontrol study. Ann Gastroenterol 2011;24:108-114.

67. Gasche C, Berstad A, Befrits R, et al. Guidelines on the diagnosis and management of iron deficiency and anemia in inflammatory bowel diseases. Inflamm Bowel Dis 2007;13:1545-1553.

68. Van Assche G, Dignass A, Bokemeyer B, et al; European Crohn's and Colitis Organisation. Second European evidence-based consensus on the diagnosis and management of ulcerative colitis part 3: special situations. J Crohns Colitis 2013;7:1-33.

69. Gasche C, Waldhoer T, Feichtenschlager T, et al; Austrian Inflammatory Bowel Diseases Study Group. Prediction of response to iron sucrose in inflammatory bowel disease-associated anemia. Am J Gastroenterol 2001;96:2382-2387.

70. Bartels U, Pedersen NS, Jarnum S. Iron absorption and serum ferritin in chronic inflammatory bowel disease. Scand $J$ Gastroenterol 1978;13:649-656.

71. Lomer MC, Kodjabashia K, Hutchinson C, Greenfield SM, Thompson RP, Powell JJ. Intake of dietary iron is low in patients with Crohn's disease: a case-control study. Br J Nutr 2004;91:141-148.

72. de Silva AD, Tsironi E, Feakins RM, Rampton DS. Efficacy and tolerability of oral iron therapy in inflammatory bowel disease: a prospective, comparative trial. Aliment Pharmacol Ther 2005;22:1097-1105.

73. Kulnigg S, Stoinov S, Simanenkov V, et al. A novel intravenous iron formulation for treatment of anemia in inflammatory bowel disease: the ferric carboxymaltose (FERINJECT) randomized controlled trial. Am J Gastroenterol 2008;103:1182-1192.

74. Alleyne M, Horne MK, Miller JL. Individualized treatment for iron-deficiency anemia in adults. Am J Med 2008;121:943-948.

75. Seril DN, Liao J, Ho KL, Warsi A, Yang CS, Yang GY. Dietary iron supplementation enhances DSS-induced colitis and associated colorectal carcinoma development in mice. Dig Dis Sci 2002;47:1266-1278.

76. Seril DN, Liao J, West AB, Yang GY. High-iron diet: foe or feat in ulcerative colitis and ulcerative colitis-associated carcinogenesis. J Clin Gastroenterol 2006;40:391-397.

77. Lugg S, Beal F, Nightingale P, Bhala N, Iqbal T. Iron treatment and inflammatory bowel disease: What happens in real practice? I Crohns Colitis 2014;8:876-880.

78. Oldenburg B, van Berge Henegouwen GP, Rennick D, Van Asbeck BS, Koningsberger JC. Iron supplementation affects the production of pro-inflammatory cytokines in IL-10 deficient mice. Eur J Clin Invest 2000;30:505-510.

79. Harris ML, Schiller HJ, Reilly PM, Donowitz M, Grisham MB, Bulkley GB. Free radicals and other reactive oxygen metabolites in inflammatory bowel disease: Cause, consequence or epiphenomenon? Pharmacol Ther 1992;53:375-408.

80. Lee TW, Kolber MR, Fedorak RN, van Zanten SV. Iron replacement therapy in inflammatory bowel disease patients with iron deficiency anemia: a systematic review and meta-analysis. J Crohns Colitis 2012;6:267-275.

81. Klein R, Herman SP, Bullock BC, Talley FA. Methyl mercury intoxication in rat kidneys. Functional and pathological changes. Arch Pathol 1973;96:83-90.

82. Schröder O, Mickisch O, Seidler U, et al. Intravenous iron sucrose versus oral iron supplementation for the treatment of iron deficiency anemia in patients with inflammatory bowel disease-a randomized, controlled, open-label, multicenter study. Am J Gastroenterol 2005;100:2503-2509. 
83. Jahn MR, Andreasen HB, Fütterer S, et al. A comparative study of the physicochemical properties of iron isomaltoside 1000 (Monofer), a new intravenous iron preparation and its clinical implications. Eur J Pharm Biopharm 2011;78:480-491.

84. Evstatiev R, Marteau P, Iqbal T, et al; FERGI Study Group. FERGIcor, a randomized controlled trial on ferric carboxymaltose for iron deficiency anemia in inflammatory bowel disease. Gastroenterology 2011;141:846-853.e1-e2.

85. Chertow GM, Mason PD, Vaage-Nilsen O, Ahlmén J. Update on adverse drug events associated with parenteral iron. Nephrol Dial Transplant 2006;21:378-382.

86. Sobrado CW, Cançado RD, Sobrado LF, Frugis MO, Sobrado MF. Treatment of anemia and improvement of quality of life among patients with Crohn's disease: experience using ferric carboxymaltose. Arq Gastroenterol 2015;52:255-259.

87. Kulnigg S, Teischinger L, Dejaco C, Waldhör T, Gasche C. Rapid recurrence of IBD-associated anemia and iron deficiency after intravenous iron sucrose and erythropoietin treatment. Am J Gastroenterol 2009;104:1460-1467.

88. Evstatiev R, Alexeeva O, Bokemeyer B, et al; FERGI Study Group. Ferric carboxymaltose prevents recurrence of anemia in patients with inflammatory bowel disease. Clin Gastroenterol Hepatol 2013;11:269-277.

89. Ali M, Rigolosi R, Fayemi AO, Braun EV, Frascino J, Singer R. Failure of serum ferritin levels to predict bone-marrow iron content after intravenous iron-dextran therapy. Lancet 1982;1:652-655.

90. Schreiber S, Howaldt S, Schnoor M, et al. Recombinant erythropoietin for the treatment of anemia in inflammatory bowel disease. N Engl J Med 1996;334:619-623.

91. Moreno López R, Sicilia Aladrén B, Gomollón García F. Use of agents stimulating erythropoiesis in digestive diseases. World $J$ Gastroenterol 2009;15:4675-4685.

92. Nakamura S, Sho M, Koyama F, et al. Erythropoietin attenuates intestinal inflammation and promotes tissue regeneration. Scand J Gastroenterol 2015;50:1094-1102.

93. Bergamaschi G, Di Sabatino A, Albertini R, et al. Prevalence and pathogenesis of anemia in inflammatory bowel disease. Influence of anti-tumor necrosis factor-alpha treatment. Haematologica 2010;95:199-205.

94. Enko D, Wagner H, Kriegshäuser G, et al. Hepcidin-25 vs. conventional clinical biomarkers in the diagnosis of functional iron deficiency. Eur J Haematol 2015;95:507-513.

95. Karlsson T. Mass spectrometry evaluation of the hepcidin- 25 assay in the differential diagnosis of iron deficiency anaemia with concurrent inflammation and anaemia of inflammation in elderly patients. Eur J Haematol 2015;95:467-471.

96. Marković M, Majkić-Singh N, Ignjatović S, Singh S. Reticulocyte haemoglobin content vs. soluble transferrin receptor and ferritin index in iron deficiency anaemia accompanied with inflammation. Int J Lab Hematol 2007;29:341-346.

97. Urrechaga E, Borque L, Escanero JF. Percentage of hypochromic erythrocytes as a potential marker of iron availability. Clin Chem Lab Med 2011;50:685-687.

98. Stallmach A, Büning C. Ferric maltol (ST10): a novel oral iron supplement for the treatment of iron deficiency anemia in inflammatory bowel disease. Expert Opin Pharmacother 2015; 16:2859-2867.

99. Levey JA, Barrand MA, Callingham BA, Hider RC. Characteristics of iron(III) uptake by isolated fragments of rat small intestine in the presence of the hydroxypyrones, maltol and ethyl maltol. Biochem Pharmacol 1988;37:2051-2057.

100. Barrand MA, Callingham BA, Dobbin P, Hider RC. Dissociation of a ferric maltol complex and its subsequent metabolism during absorption across the small intestine of the rat. $\mathrm{Br} J$ Pharmacol 1991;102:723-729.

101. Hashizume M, Uchiyama Y, Horai N, Tomosugi N, Mihara M. Tocilizumab, a humanized anti-interleukin-6 receptor antibody, improved anemia in monkey arthritis by suppressing IL-6induced hepcidin production. Rheumatol Int 2010;30:917-923.

102.Xiao JJ, Krzyzanski W, Wang YM, et al. Pharmacokinetics of anti-hepcidin monoclonal antibody $\mathrm{Ab} 12 \mathrm{~B} 9 \mathrm{~m}$ and hepcidin in cynomolgus monkeys. AAPS J 2010;12:646-657. 